\title{
Lifetime Accumulation of Microplastic in Children and Adults
}

\author{
Nur Hazimah Mohamed Nor,* Merel Kooi, Noël J. Diepens, and Albert A. Koelmans
}

Cite This: https://dx.doi.org/10.1021/acs.est.0c07384

Read Online

ABSTRACT: Human exposure to microplastic is recognized as a global Plastic sources problem, but the uncertainty, variability, and lifetime accumulation are unresolved. We provide a probabilistic lifetime exposure model for children and adults, which accounts for intake via eight food types and inhalation, intestinal absorption, biliary excretion, and plastic-associated chemical exposure via a physiologically based pharmacokinetic submodel. The model probabilistically simulates microplastic concentrations in the gut, body tissue, and stool, the latter allowing validation against empirical data. Rescaling methods were used to ensure comparability between microplastic abundance data. Microplastic $(1-5000 \mu \mathrm{m})$ median intake rates are 553 particles/capita/day (184 ng/capita/day) and 883 particles/capita/day (583

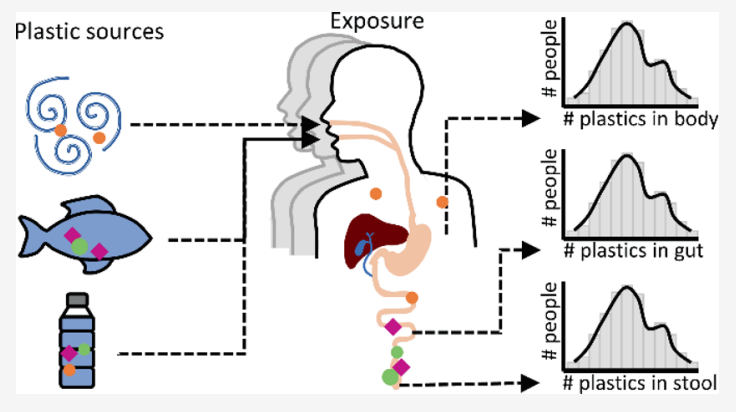
$\mathrm{ng} /$ capita/day) for children and adults, respectively. This intake can irreversibly accumulate to $8.32 \times 10^{3}\left(90 \% \mathrm{CI}, 7.08 \times 10^{2}-1.91\right.$ $\left.\times 10^{6}\right)$ particles/capita or $6.4\left(90 \% \mathrm{CI}, 0.1-2.31 \times 10^{3}\right) \mathrm{ng} /$ capita for children until age 18 , and up to $5.01 \times 10^{4}(90 \% \mathrm{CI}, 5.25 \times$ $\left.10^{3}-9.33 \times 10^{6}\right)$ particles/capita or $40.7\left(90 \% \mathrm{CI}, 0.8-9.85 \times 10^{3}\right) \mathrm{ng} /$ capita for adults until age 70 in the body tissue for $1-10 \mu \mathrm{m}$ particles. Simulated microplastic concentrations in stool agree with empirical data. Chemical absorption from food and ingested microplastic of the nine intake media based on biphasic, reversible, and size-specific sorption kinetics, reveals that the contribution of microplastics to total chemical intake is small. The as-yet-unknown contributions of other food types are discussed in light of future research needs.

\section{INTRODUCTION}

Humans are exposed to microplastics (MPs) everyday. ${ }^{1,2}$ These small particles $(1-5000 \mu \mathrm{m})$ are omnipresent in our food, including water and beverages, and air. ${ }^{3-7}$ The first evidence of MP in human stools proves that these particles are indeed ingested and can pass through the gastrointestinal (GI) tract. $^{8}$ This has raised concerns about the actual exposure and impact on human health. ${ }^{6}$ While it is widely accepted that humans are exposed to MPs, the magnitude, uncertainty, and variability of MP exposure concentrations and intake rates globally remain unknown. These uncertainties have resulted in many controversies regarding the potential risks that MPs may pose to human health. 9,10

To date, only two studies have performed human exposure assessments for MP by estimating total intake from different intake media, deterministically. ${ }^{1,2}$ A major limitation in the aforementioned studies is that there are discrepancies in the databases used, due to the differences in MP definitions and analytical techniques. Zhang et al. ${ }^{1}$ acknowledged these discrepancies and thus made a conscientious effort to use more comparable data. However, such methods would fail to estimate MPs from other size ranges, inaccurately representing the full MP continuum $(1-5000 \mu \mathrm{m}) .{ }^{11,12}$ Furthermore, single exposure estimates based on average exposure rates may not well represent the distribution of global MP intake rates.

Besides exposure, the fate and transport of ingested MPs in the human body, which include intestinal absorption and biliary excretion, have not been addressed in earlier studies and remained largely unknown. ${ }^{9}$ Accumulation of MPs in the body tissues could cause physical stress and damage, inflammation, oxidative stress, and immune responses. ${ }^{13}$ To date, effect studies examining MPs on human cells found little evidence of impact on cell viability. ${ }^{14-17}$ However, it is uncertain if the range of exposure concentrations used in such studies is truly representative of the MP accumulated in body tissues.

Another speculated hazard from exposure to MPs is chemical toxicity. Plastics contain a huge variety of added and non-intentionally added chemicals. ${ }^{18}$ Furthermore, MPs found in food types such as seafood and salt may have adsorbed chemicals from the environment it originated from. ${ }^{19}$ The importance of MPs to influence chemical exposure in humans has been highly debated. ${ }^{4,9}$ Past studies have only considered $100 \%$ leaching of the chemicals from the particles. $^{3,6,20}$ Although legitimate as a worst case scenario, this is not realistic since only a part of the chemicals in the particles is bioavailable due to kinetic constraints and limited gut residence time. The body also accumulates these chemical

Received: November 1, 2020

Revised: February 17, 2021

Accepted: February 26, 2021 


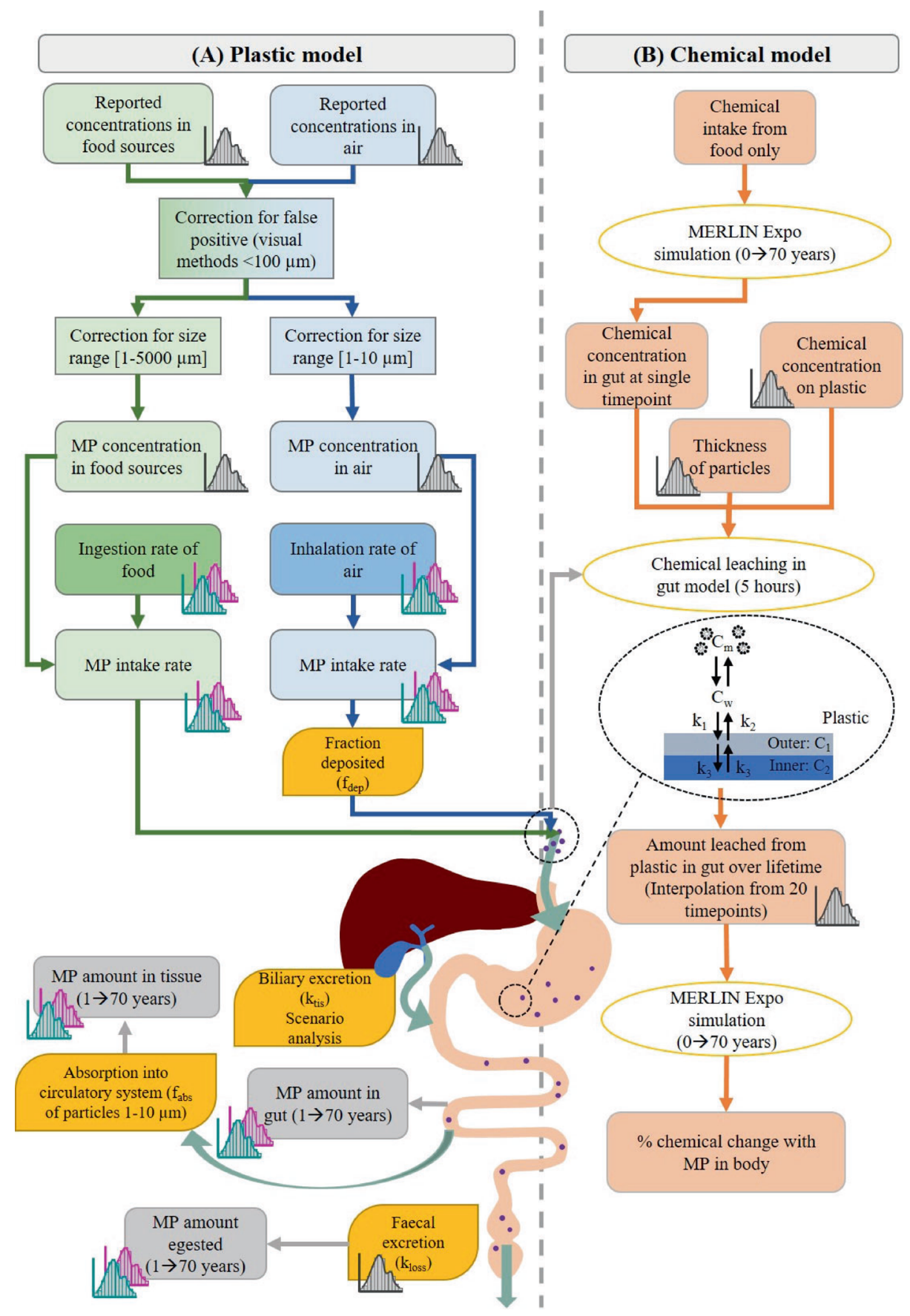

Figure 1. Schematic overview of the workflow for (A) the plastic model and (B) chemical model. (A) Green boxes and arrows indicate MP from food; blue boxes and arrows indicate MP from air. Yellow boxes represent the parameter inputs. Grey boxes and arrows represent the outputs: the MP amount accumulated in gut and tissue and amount egested. (B) Total MP intake calculated from the plastic model (shown at the inlet of the stomach) was used to calculate total chemical leached from MP in the chemical model. $C_{\mathrm{m}}$ is the chemical concentration in gut fluid micelles, $C_{\mathrm{W}}$ is the chemical concentration in water in the gut, $C_{1}$ and $C_{2}$ are the chemical concentrations in the outer and inner phases of MP, respectively; $k_{1}$ and $k_{2}$ are the sorption and desorption rate constants, respectively; $k_{3}$ is the intrapolymer rate constant. Orange boxes represent the inputs for the chemical model and orange-outlined ovals represent the models used to calculate the chemical distributions and leaching from MP. Histogram symbols represent inputs with distributions. Green histogram: child (1-18 years); pink histogram: adults (19-70 years).

compounds through other routes of exposure, such as direct ingestion of food and inhalation. ${ }^{21}$ Some of these compounds would cause risk if total concentrations are higher than their threshold effect concentrations, whereas carcinogenic compounds do not have a dose threshold level. ${ }^{22}$ To evaluate the actual risk and relative importance of $\mathrm{MP}$ as a chemical carrier, the actual MP intake amount from known food types and fraction of chemical leached as well as its associated uncertainties need to be quantified for the full MP continuum and chemicals residing in the particles.

The aims of the present study are to estimate the MP exposure in children and adults via eight food types and inhalation, and to assess the chemical contribution of MPs in relation to total chemical intake. Furthermore, we aim to compare the variability of MP abundance in the known eight food types and air. To this end, a probabilistic lifetime MP 
exposure model for children and adults is developed that accounts for the full variability of MP across different known intake media and global intake rates. The accumulation of MP in the body tissue and the amount egested in the stool are also determined and quantified in terms of particle number and mass distributions. To understand the potential risk of MP due to plastic-associated chemicals, the transfer of a relevant suite of chemicals from ingested MPs was simulated via kinetic modeling under realistic conditions whereby a human is also exposed to chemicals from dietary intake. Four representative chemicals that are commonly detected in plastic ${ }^{23,24}$ were investigated: (1) benzo(a)pyrene ( $\mathrm{BaP}),(2)$ di(2-ethylhexyl)phthalate (DEHP), (3) 3,3',4,4',5-pentachlorobiphenyl (PCB126), and (4) lead. These chemicals were selected as they are widely known as main environmental pollutants due to the high carcinogenic potencies of the organic compounds, ${ }^{25-27}$ while lead toxicity can lead to blood disorders and damage to the nervous system. ${ }^{28}$

\section{MATERIALS AND METHODS}

The probabilistic exposure assessment toolkit, Human Exposure Assessment for Small mIcroplastics (HEASI), comprises of two separate components (Figure 1): (A) The "Plastic Model", which calculates MP abundance in gut, tissue, and stool with kinetic mass balance equations describing transport processes in the GI tract; and (B) the "Chemical Model" which uses the calculated MP intake from (A) to quantify chemical transfer from MP to the human body under realistic feeding conditions. Below, we provide the main features and equations of the assessment. A full description and list of fitted distribution parameters are provided in the Supporting Information (SI). Compiled databases from literature (Data S1-S6) are accessible in the following data depository: https://github.com/nhazimah/heasi. Because microplastic is a diverse material and input data show considerable uncertainty, the assessment was done probabilistically via Monte Carlo (MC) simulations, with $n=10,000$ iterations for each of the calculation steps. Ranges presented subsequently relate to the $90 \%$ confidence interval.

Plastic Model. The lifetime exposure to MPs for humans is modeled as a mass balance of intake (i.e., dietary and inhalation) and loss processes in the human body (via the GI tract). ${ }^{29,30}$ The amount of MP in the GI tract per person, $C_{\mathrm{MP}}$ (particles/capita), per day is calculated as

MP in the GI tract $(t)=(\mathrm{A})$ intake from food types $+(\mathrm{B})$ intake from air $+(C)$ transfer of accumulated MP in the body back to the GI tract - (D) loss from egestion.

In a mathematical form with terms $\mathrm{A}, \mathrm{B}, \mathrm{C}$, and $\mathrm{D}$ in the same order

$$
\begin{aligned}
\frac{\mathrm{d} C_{\mathrm{MP}}}{\mathrm{d} t}= & \left(1-f_{\mathrm{abs}} \cdot f_{\mathrm{a}, n}\right) \sum_{i=1}^{n}\left(\operatorname{Ir}_{i} \cdot C_{i}\right)+\left(1-f_{\mathrm{abs}}\right) \\
& \left(f_{\mathrm{dep}} \cdot \operatorname{InR} \cdot C_{\mathrm{a}}\right)+k_{\mathrm{tis}} \cdot C_{\mathrm{tis}}-k_{\text {loss }} \cdot C_{\mathrm{MP}}
\end{aligned}
$$

The amount of MPs accumulated in the whole body tissue can then be calculated as

$$
\frac{\mathrm{d} C_{\mathrm{tis}}}{\mathrm{d} t}=f_{\mathrm{abs}} \cdot f_{\mathrm{a}, n} \sum_{i=1}^{n}\left(\operatorname{Ir}_{i} \cdot C_{i}\right)+f_{\mathrm{abs}} \cdot\left(f_{\mathrm{dep}} \cdot \operatorname{InR} \cdot C_{\mathrm{a}}\right)-k_{\mathrm{tis}} \cdot C_{\mathrm{tis}}
$$

For intake from food (eq 1, term A), index $i$ refers to the $n$ food types assessed in the present study (here, $n=8$, i.e., fish, mollusc, crustacean, tap water, bottled water, salt, beer, and milk), $C_{i}$ is the MP concentration per media in terms of number concentrations (particles/g) and $\mathrm{Ir}_{i}$ is the associated daily ingestion rate (g/capita/day). We also accounted for intestinal absorption $\left(f_{\mathrm{abs}}\right)$ as phagocytosis, endocytosis, and persorption have been identified as mechanisms explaining uptake of particles $<10 \mu \mathrm{m} .{ }^{9,13,31-34}$ The fraction of particles that is taken up by the human GI tract is relatively unexplored. Most literature sources claim that intestinal absorption is low, reaching up to $0.3 \%$ for particles with sizes up to $\sim 2$ to $3 \mu \mathrm{m}$ based on rodent and ex vivo models. ${ }^{14,35-37}$ Here, we assumed a fraction of particles, $f_{\mathrm{abs}}$ of $0.3 \%$ of all $1-10 \mu \mathrm{m}$ particles, is absorbed in the intestines. This is a conservative average estimate based on the range of absorbed fractions $(0.2-0.45 \%)$ measured in vitro using human colon tissue. ${ }^{38}$ The number of particles in the $1-10 \mu \mathrm{m}$ size range is based on the fraction, $f_{\mathrm{a}, n}$, of the total number of ingested particles, complying to the $1-5000 \mu \mathrm{m}$ power-law size distribution, which is explained in the next section (eq 4). This bioavailable fraction of particles is represented as an uptake process in the first term of eq 2 .

MP intake from the air compartment (eq 1, term B) is calculated with MP concentration $(1-10 \mu \mathrm{m})$ in air, $C_{\mathrm{a}}$ (particles $\left./ \mathrm{m}^{3}\right)$, and the inhalation rate, $\operatorname{InR}\left(\mathrm{m}^{3} /\right.$ capita/day). A fraction of inhaled particles is assumed to be deposited in the nasopharyngeal cavity $\left(f_{\text {dep }}\right)$ and then swallowed in the GI tract. This fraction is assumed as a constant of $0.83 .^{39}$ Swallowed particles from the air intake are also subjected to intestinal absorption (second term in eq 2), and hence, $f_{\mathrm{abs}}$ is also included in this term.

Removal of MP from the tissue, $C_{\text {tis }}$ (particles/capita), is modeled as biliary excretion through the GI tract (term $\mathrm{C}$ in eq 1 and the third term in eq 2). Because the biliary excretion rate constant, $k_{\mathrm{tis}}\left(\mathrm{day}^{-1}\right)$, is unknown for humans and microplastics, this was addressed using a scenario-based approach to describe zero, minimum, median, and maximum biliary excretion kinetic rate values based on three rat and mouse studies on nanoparticles $\left(<1 \mu \mathrm{m}^{40}\right)$ (Table S1). ${ }^{41-43}$ Therefore, we assumed that the transfer rate of this pathway is similar for both MPs and nanoparticles, which are able to access organs and penetrate cell membranes.

Loss via egestion (eq 1 , term $\mathrm{D}$ ) is modeled with a loss rate constant based on stool frequencies, ${ }^{44-49} k_{\text {loss }}\left(\right.$ day $\left.^{-1}\right)$, assuming that MP particles are not trapped in the GI tract. ${ }^{8}$ The amount of MP egested per stool mass per capita, $C_{\text {stool }}$ (particles/g stool/capita), can be further calculated based on the gut steady state concentrations $\left(C_{\mathrm{MP}, \mathrm{SS}}\right)$ and stool mass excreted per capita per day, $M_{\text {stool }}$ (g stool) (eqs S1 and S2). ${ }^{49-53}$

Plastic Model Inputs and Parameterization. A literature review was performed to identify studies that reported plastic concentrations in media relevant for human intake. Search terms included: microplastic, plastic, fish, seafood, salt, human, air, food. Searches were performed until March 2020 using search engines Scopus and Google Scholar, and only studies reporting original concentration data were reviewed. Targeted searching was also conducted for databases or reviews published by nongovernmental organizations and governmental agencies. A total of 134 studies was identified reporting MP concentrations in nine media: (1) fish, (2) mollusc, (3) crustacean, (4) tap water, (5) bottled water, (6) beer, (7) milk, (8) salt, and (9) air (Data S1). For each source, a set of criteria and assumptions was made to ensure the quality and utility of 
data for subsequent model analysis (see the Supporting Information).

Food consumption data were collected from FOSCOL$\mathrm{LAB}^{54}$ a database collated by the World Health Organization (WHO) and Food and Agricultural Organization (FAO) on chronic individual food consumption in different countries for different age classes (https://apps.who.int/foscollab). The list of search terms is provided in Table S2. Total mean ingestion rates were used to represent the whole population (i.e., including nonconsumers of the food) and the data were recategorized into two age groups: children ( $1-18$ years) and adult (19-70 years). Inhalation rates were based on two studies $^{55,56}$ and redefined according to the aforementioned age groups (Table S3).

As most studies on MP occurrence in media associated with human intake are still limited to pioneering research, some of the methodologies that have been implemented thus far are not yet fully adequate. ${ }^{57}$ To account for these inadequacies, we have applied a series of calculations to allow for better comparability among data with varying qualities, hence improving data utility. The model parameterization comprises the following three corrections (Figure 1A), which are explained hereafter and in full detail in the Supporting Information.

Correction 1: False Positives. Out of the 871 datasets acquired for the exposure assessment, 203 datasets did not conduct further spectroscopic identification to confirm if the particles are indeed polymer-based. ${ }^{57,58}$ Among these 203 datasets, $35 \%$ of them reported that their size detection limit was below $100 \mu \mathrm{m}$. As these studies may have overestimated the MP concentrations, we applied a correction factor to account for potential false positives. False positive rates for MP visual identification have been reported by Lenz et al., ${ }^{59}$ and the success rates for $<50$ and $50-100 \mu \mathrm{m}$ are 63 and $67 \%$ respectively. Therefore, we assumed $65 \%$ (i.e., median success rates of $<50$ and $50-100 \mu \mathrm{m}$ ) of the particles had been correctly identified as MPs when the lower size limit detected by the study was below $100 \mu \mathrm{m}$. For particles above $100 \mu \mathrm{m}$, it is assumed that one can correctly identify MP through the particle texture and shapes.

Correction 2: Realignment of the Size Range. To allow for comparison of MP concentration data from studies targeting different size ranges, we used the size realignment method of Koelmans et al. ${ }^{12}$ supported by studies ${ }^{60,61}$ that have shown that fragmented plastic particles in the environment generally conform to a power-law size distribution. To realign the MP concentrations from different size ranges, particle size distributions (PSDs) for the different media in the present study are required. We assumed the PSDs for food to be different from that for air. The detailed approach for extracting this information is explained in the Supporting Information. We fitted the PSDs for 29 datasets from our literature review with the power-law function (Figure S1 and Table S4), according to Koelmans et al. ${ }^{12}$ (see the Supporting Information).

Using the obtained power-law exponent, $\alpha$, the MP concentrations found within any size range can then be translated into the expected MP concentrations for the default size range by using a correction factor $\left(\mathrm{CF}_{\text {scale }}\right)$, which scales the integral of eq S3 for the measured $(M)$ size range against the default $(D)$ range: ${ }^{12}$

$$
\mathrm{CF}_{\text {scale }}=\frac{\int_{x_{0 M}}^{x_{1 M}} C x^{-\alpha}}{\int_{x_{0 D}}^{x_{1 D}} C x^{-\alpha}}=\frac{x_{1 M}^{1-\alpha}-x_{0 M}^{1-\alpha}}{x_{1 D}^{1-\alpha}-x_{0 D}^{1-\alpha}}
$$

For the food types, we adjusted the measured MP concentrations to a default MP size range of $1-5000 \mu \mathrm{m} .{ }^{12}$ For air, the datasets were adjusted to a default range of $1-10$ $\mu \mathrm{m}$ because it has been demonstrated that only particles in this size range are filtered in the nose and may be swallowed via the nasopharyngeal pathway. ${ }^{9,39}$ Based on the available PSDs from the aforementioned 29 datasets, two power-law exponents were defined, one for food $\left(\alpha_{\text {food }}\right)$ and one for air $\left(\alpha_{\text {air }}\right)$. The extrapolation of the MP concentrations to the default size range was carried out using eq 3 with $\alpha$ values selected from the probability density functions (PDFs) defined for $\alpha_{\text {food }}$ or $\alpha_{\text {air }}$, via MC simulation in $\mathrm{R}^{62}$ Convergence of the PDFs for the realigned MP concentrations was obtained with 1000 iterations.

The parameter $f_{a, n}$ can be calculated following the same principle as in eq 3 , as a ratio of the integral between the interval $1-10 \mu \mathrm{m}$ to the integral between the interval $1-5000$ $\mu \mathrm{m}$ :

$$
f_{\mathrm{a}, n}=\frac{\int_{1}^{10} C x^{-\alpha_{\mathrm{food}}}}{\int_{1}^{5000} C x^{-\alpha_{\mathrm{food}}}}=\frac{10^{1-\alpha_{\mathrm{food}}}-1^{1-\alpha_{\mathrm{food}}}}{5000^{1-\alpha_{\mathrm{food}}}-1^{1-\alpha_{\mathrm{food}}}}
$$

Correction 3: Translation of Gut to Muscle MP Concentration in Fish. The MP concentrations in the GI tract or stomach of fish, which were often reported in studies, were used to estimate the MP concentrations in the edible muscle tissue of the fish. Most studies investigating MP occurrence in fish were conducted to understand if plastic was ingested by the species. The direct application of these MP concentrations is not useful for human dietary intake in our exposure assessment as only a small fraction of the world population eats the fish stomach. Therefore, to estimate the MP concentration in the muscle tissue, we calculated the ratio between the plastic concentrations in the muscle and gut of the fish $\left(\mathrm{CF}_{\mathrm{mg}}\right)$ based on empirical data for seven fish species. ${ }^{63,64}$ The derivation of $\mathrm{CF}_{\mathrm{mg}}$ and its distribution is detailed in the Supporting Information (Table S5).

Distributions were fitted to the MP concentrations in different intake media and physiological data with packages from $\mathrm{R}^{65-68}$ Datasets with zero observations were omitted for the distribution fitting; however, the probability of zero observations was accounted for by assigning a fraction of the generated random values from the MC simulations to zero observation. Table S6 provides an overview of the inputs used for the MP exposure model and the most appropriate distribution functions selected based on goodness-of-fit analyses (see the Supporting Information for details and Data S2). Some distributions were represented as triangular distributions when few data were available.

Plastic Model Simulations and Validation. The MP amount per capita $\left(C_{\mathrm{MP}}\right)$ was calculated numerically with the deSolve package ${ }^{69}$ in $\mathrm{R}$. We modeled two age group scenarios: a child scenario where exposure starts at 1 year and continues up to 18 years, and an adult scenario where exposure continues from 18 years and goes on to the age of 70 years (UN average global life expectancy in 2019).

Number concentrations and mass concentrations are both relevant metrics for exposure and toxicological assessments. The plastic model was first applied to number concentrations 
of MP particles. Then, particle numbers were converted to mass concentrations based on size, shape, and density distributions of the particles (see the Supporting Information). These properties were defined from the literature survey in the present study (Data S3 and S4). PDFs were fitted to the data for each property, and the mass per particle was calculated for food and air, respectively (Figure S2 and Table S7).

The amount of MP egested per stool mass was used as an endpoint to validate against empirical data for the MP amount in stool. ${ }^{8}$

Chemical Model. The chemical transfer from MP under realistic feeding conditions is assessed via a two-step approach using two submodels (Figure 1B). First, we used an established physiologically-based pharmacokinetic (PBPK) model in MERLIN Expo V3.0 (Man model), ${ }^{70}$ which predicts the distribution of chemicals in the human body. A full description of the chemical intake data and literature used to obtain PBPK parameters are provided in the Supporting Information.

The second step consists of two separate approaches to predict the amount of hydrophobic organic chemicals (HOCs) and lead leached from MPs in the gut. For HOCs, the chemical exchange is quantified based on kinetic parameters and the concentration gradient between MPs and gut, using a previously published biphasic kinetic model for organic chemicals sorbed on MPs. ${ }^{71}$ The chemical exchange in the fast and slow sorbing compartments is modeled as

$$
\frac{\mathrm{d} C_{1}}{\mathrm{~d} t}=\frac{k_{1}}{f_{1} \cdot\left(\text { Intake } \cdot m_{i} / V_{\text {gut }}\right)} \cdot C_{w}-\left(k_{2}+k_{3}\right) \cdot C_{1}+k_{3} C_{2}
$$

$$
\frac{\mathrm{d} C_{2}}{\mathrm{~d} t}=k_{3} C_{1}-k_{3} C_{2}
$$

where $C_{1}$ and $C_{2}$ are chemical concentrations in the fast and slow reservoirs of the MP $(\mu \mathrm{g} / \mathrm{kg}) ; k_{1}$ is the fast sorption rate constant $\left(\mathrm{d}^{-1}\right), k_{2}$ is the desorption rate constant $\left(\mathrm{d}^{-1}\right)$, and $k_{3}$ is the intrapolymer rate constant $\left(\mathrm{d}^{-1}\right)$; and $f_{1}$ is the fast reservoir fraction (dimensionless). The rate constants for desorption into gut fluids were quantified in earlier research ${ }^{71}$ and were rescaled to account for the diversity of particle sizes based on Fick's law of diffusion (see the Supporting Information). Intake is the number of MP taken in per media category per capita (particles/capita), $V_{\text {gut }}$ is the volume of the gut, which we assumed to be $0.6 \mathrm{~L}^{72}$ (note that this choice is arbitrary because the total amount of chemical leached $(\mu \mathrm{g})$ is used in subsequent calculations), $C_{\mathrm{w}}$ is the chemical concentration in the water of the gut calculated based on the concentration in the gut lipids $\left(C_{\text {gut }}\right)$ simulated from the aforementioned PBPK model at a specific age assuming the fraction of lipids in gut $\left(f_{\text {lip.gut }}\right)$ is $0.05:^{73}$

$$
C_{\mathrm{w}}=\frac{C_{\text {gut }}}{f_{\text {lip.gut }}} / K_{\text {ow }}
$$

with $\log K_{\text {ow }}=6.13(\mathrm{BaP}), 7.6(\mathrm{DEHP})$, and 6.89 (PCB126). ${ }^{74-76}$ At the time of intake $(t=0)$, the chemical concentrations in the plastic compartments $C_{1}$ and $C_{2}$ are assumed to be in equilibrium $\left(C_{1}=C_{2}\right)$, and the concentration values are based on chemical concentrations in MPs found in intake media, which is discussed in the next section.

As for lead, empirical data was used based on Godoy et al. ${ }^{77}$ (i.e., 23.2\% leaching during the intestinal absorption phase) to estimate the contribution of lead intake from MP to total dietary lead exposure using the PBPK model.

Chemical Model Inputs. For the chemical model, four representative chemicals were investigated: (1) $\mathrm{BaP}$, (2) DEHP, (3) PCB126, and (4) lead. Literature survey on concentrations of these chemicals in organisms from the pelagic or littoral zone and atmospheric particulate matter chemical concentrations was performed (Data S5). These concentrations were used as proxies for plastic found in seafood and air, respectively. Additionally, the literature was reviewed for chemical concentrations on plastic from food packaging or manufacturing processes, which were used as proxy for the beverages in the present study. Further explanation for using these proxies is provided in the Supporting Information.

Simulation of Chemical Distributions in the Human Body. The distribution of chemicals in the tissues and organs of the human body was simulated with the Man model in MERLINExpo V3.0 from 0 to 70 years. Daily chemical intake of the four representative chemicals was based on selected literature: $\mathrm{BaP},{ }^{78,79}$ DEHP, ${ }^{80-82}$ PCB126, $^{83}$ and lead ${ }^{84}$ (Data S6). For PCB126 and lead, intake through inhalation was not considered as atmospheric concentrations are negligible compared to intake through food. ${ }^{85,86}$

Chemical Leaching from Plastic in Gut. We parameterized the chemical exchange of HOCs in the present study for the case of low density polyethylene (LDPE) as it is a common polymer type ${ }^{57}$ and has the best available information thus far. ${ }^{71}$ The amount of chemical leached from LDPE in the gut was calculated using the $\mathrm{MC}$ approach and the aforementioned biphasic reversible (de-) sorption model. First, we generated 10,000 particles $(i)$ with different sizes for MP in food and air, respectively, based on the aforementioned power-law exponents (i.e., $\alpha_{\text {food }}$ and $\left.\alpha_{\text {air }}\right)$. The mass per particle $\left(m_{i}\right)$ was calculated for each $i$ th particle using the density range of LDPE (Data S4) and shape distributions (see the Supporting Information).

The MP intake amount calculated with the plastic model for the different media was redefined into four categories: (1) pelagic zone (fish and salt), (2) littoral zone (mollusc and crustacean), (3) packaging or manufacturing (tap water, bottled water, beer, and milk), and (4) atmosphere. Finally, the chemical concentrations on MP for each category were also simulated probabilistically (Table S8).

The chemical concentrations in the fast $\left(C_{1}\right)$ and slow $\left(C_{2}\right)$ reservoirs of the $i$ th particle for each media category were then solved numerically for a duration of $5 \mathrm{~h}$ per iteration (i.e., the average transit time through the stomach and small intestine $\left.{ }^{87}\right)$. Boundary conditions at gut transit time zero were the initial chemical concentrations in MP and the background chemical concentration in the gut from food only, as obtained from the MERLIN-Expo Man model. Calculations were performed in $\mathrm{R}$ using the deSolve package ${ }^{69}$ and iterated 10,000 times for each individual particle size. The amount of chemicals $(\mu \mathrm{g})$ released from MPs of each media category after the gut transit time was then calculated based on the plastic intake mass of that source (i.e., Intake $\times m_{i}$ ). The entire model simulation was then repeated for selected timepoints $(n=20)$ between 1 and 70 years of age having different chemical concentrations in the gut, based on the man model simulation. The 50th and 97.5th percentiles of the distributions of total chemical leached from all MP intake media for these 20 timepoints were then interpolated with a cubic spline function 
to estimate the chemical intake from MPs in all years. Subsequently, we resimulated the chemical biodistribution using the Man model with the added intake of chemical exposure via MPs and calculated the percentage change of chemical concentrations in the adipose tissue (HOCs) and in blood (lead). A positive change reflects an increased chemical concentration in the tissue due to chemical desorption from ingested MPs, whereas a negative change reflects a reduced concentration due to absorption of chemical from the GI tract by ingested MP..$^{30,71,88,89}$

\section{RESULTS AND DISCUSSION}

Distributions of MP Occurrence in Food and Air. The power-law exponent for food $\left(\alpha_{\text {food }}\right)$ was defined as a truncated normal distribution with a mean of $1.60 \pm 0.51(n=13)$ (Table S1), and for air $\left(\alpha_{\text {air }}\right)$, it was defined as a triangular distribution with a minimum of 1.89 , maximum of 2.24 , and a mode of 2.06 following two air studies. ${ }^{90,91}$ Based on the fitted mean PSD for food, $75.3 \%$ of the full MP continuum (1-5000 $\mu \mathrm{m})$ consists of small particles $(1-10 \mu \mathrm{m})$, in terms of number concentrations. For air, these particles account for $91.4 \%$ and thus represent a significant proportion of the full MP size range. However, only $22.7 \%$ of the datasets used in the present study were able to account for these particles. Rescaling the MP concentrations to the full MP size continuum was thus necessary to not underestimate the concentrations. ${ }^{12}$ Furthermore, in doing so, we accounted for the smallest particles that are more relevant for accumulation in the body and potential toxicity. ${ }^{9,13}$ The estimated power-law exponent for food in the present study is in excellent agreement with the exponents reported previously for PSDs of MPs in marine and freshwater environments. ${ }^{61}$ Other studies have also reported power-law exponents between 1.2 and 2.93 for plastic fragmentation through impaction ${ }^{92}$ or natural processes in the ocean. ${ }^{60}$ The variations in the exponents may be a result of other processes at play, such as size selective emissions.

MP occurrence in eight food types and air were compiled as data were available in sufficient detail and quality for these intake media at the point of our analysis. The concentrations in food were rescaled to the full MP continuum and corrected for potential false positives accordingly (Figure 2A, Figure S3). We found that among seafood, molluscs had the highest MP concentration distribution with 50th and 95th percentiles of 8.07 particles/g TWW and 428.4 particles/g TWW, respectively (Table S6). These percentiles are about four times higher than the concentrations found for crustaceans and up to 40 times higher than fish. Furthermore, fish had a higher non-occurrence than the other seafood types. This may be partly attributed to the feeding ecology of the organisms and distribution of MPs in different environmental compartments. Molluscs and crustaceans are mainly filter feeders and feed on suspended materials, which may increase the likelihood of MP ingestion. $^{93}$ Moreover, molluscs are usually located at the bottom of the water bodies within the sediments, where there may be a high abundance of MPs deposited. ${ }^{94}$

Remarkably, the distributions of MP concentrations in the liquids analyzed in the present study have a similar order of magnitude, with 50th percentiles ranging from 125 to 337 particles/L (Table S6). Nevertheless, bottled water has 2.5 times higher median concentrations than the other packaged beverages (i.e., beer and milk). This suggests that the MPs mainly come from the polymer packaging material, ${ }^{95}$ since
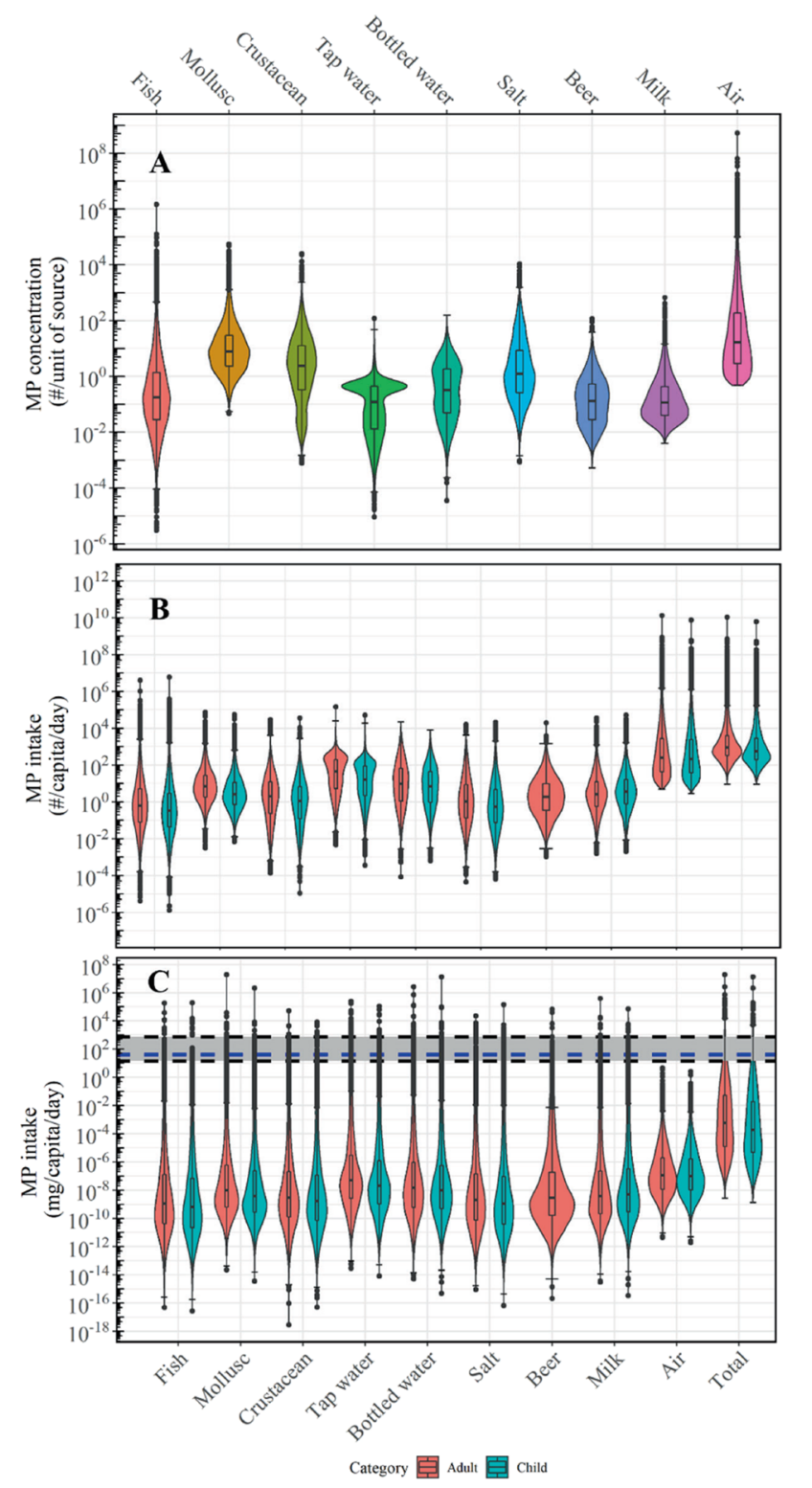

Figure 2. MP concentrations and intake in each source. (A) Violin plots of MP concentration in food $(1-5000 \mu \mathrm{m})$ and air $(1-10 \mu \mathrm{m})$. Concentrations are presented as per gram of body wet weight (BWW) for fish and crustacean, per gram of tissue wet weight (TWW) for mollusc, per liter for all liquids, per gram for salt, and per cubic meter for air. (B) Violin plots of MP number intakes (particles/capita/day) and total MP number intake from food and air for an adult and child. (C) Violin plots of MP mass intakes (mg/capita/day) and the total MP mass intake from food and air for an adult and child. Black dashed lines and the shaded gray region $(14-714 \mathrm{mg} /$ capita/day) indicates the range of mass intake estimation by $\mathrm{WWF},{ }^{101}$ and the blue dashed line $(40 \mathrm{mg} / \mathrm{capita} /$ day $)$ indicates the mass intake of inorganic particles. ${ }^{102}$ The box plot is showing the median (middle line) and interquartile range (box length). Note that data are only realistic within the $95 \%$ confidence interval (horizontal line on the whiskers of the box plot).

beer and milk are packaged in glass, aluminium cans, ${ }^{96,97}$ or tetrapak cartons. $^{98}$

Salt has a wide distribution of MP concentrations based on 162 datasets from 65 locations, ranging across more than three orders of magnitude. The 50th and 95th percentiles are $1.29 \times$ $10^{3}$ and $1.19 \times 10^{5}$ particles/kg, respectively (Table S6). 
Zhang et al. ${ }^{1}$ recently reviewed the MP abundances in table salt globally and found that the abundances varied widely, with the highest concentration at $2.0 \times 10^{4}$ particles $/ \mathrm{kg}$. However, the authors acknowledged that the reviewed datasets could not be compared with each other due to differences in analytical methods used. Therefore, the present study has addressed this non-alignment of datasets using a novel approach so that they represent the full MP continuum and can be better compared.

The concentration of inhalable MPs $(1-10 \mu \mathrm{m})$ in air is 36.3 particles $/ \mathrm{m}^{3}$ and 19,000 particles $/ \mathrm{m}^{3}$ at the 50 th and 95 th percentiles, respectively. Standards for particulate matter smaller than $10 \mu \mathrm{m}\left(\mathrm{PM}_{10}\right)$ exist, and according to the WHO, the annual mean of $\mathrm{PM}_{10}$ in ambient outdoor air should be below $20 \mu \mathrm{g} / \mathrm{m}^{3}$. 99 For comparison, we converted the MP particle number concentrations to mass concentrations based on the mass per particle PDF for air and found that the 95th percentile of the distribution is about $0.011 \mu \mathrm{g} / \mathrm{m}^{3}$. Based on the WHO's air quality database from 2018 , the average global $\mathrm{PM}_{10}$ level is $72 \mu \mathrm{g} / \mathrm{m}^{3}$ and the lowest level by region is in the high-income countries in Europe with a concentration of 22 $\mu \mathrm{g} / \mathrm{m}^{3}{ }^{100}$ Therefore, the MP concentration in the air has a negligible contribution to the $\mathrm{PM}_{10}$ levels, even at the 95th percentile.

Lifetime Exposure to Microplastic. Number of MP Intake Per Capita. We estimated the global MP intake per capita per day from each of the nine media probabilistically (Figure 2B). The medians of the total MP number intake rates found in this study are $553\left(52.5-1.37 \times 10^{5}\right)$ particles/ capita/day for children and $883\left(86.4-1.68 \times 10^{5}\right)$ particles/ capita/day for adults, and the distributions were highly right skewed. Mean exposure amounts for the American population estimated by Cox et al. ${ }^{2}$ fall in the lower 10th percentile of the ranges estimated in the present study. This is because the aforementioned study did not rescale particle number concentrations to the full MP size continuum. This is corroborated by our earlier finding that small particles (1-10 $\mu \mathrm{m})$ make up about 75 to $90 \%$ of the overall particle distribution and neglecting them results in a huge underestimation. Furthermore, single point estimates of consumption rates for the American population may not be representative of the global consumption rate distribution. In a later review by Zhang et al., ${ }^{1}$ MP intake ranges in salt, drinking water, and inhalation were estimated. The median and maximum values of the range reported for salt and air are close to the upper 90th percentile range of MP intake in our study. However, the range reported for drinking water was lower than the 50th percentile of our distribution range for tap water. Although previous studies have estimated MP intakes within the $95 \%$ confidence interval of our distribution, their single point estimates and ranges did not account for the full variability of MP from different known intake media and the global consumption rates, which is done here for the first time.

Mass of MP Intake Per Capita. Several past studies and reviews have converted particle number concentrations using conversion factors with a constant mass per particle factor $^{6,20,37,95}$ to evaluate the chemical risks of MP. Particle mass was calculated simplistically assuming spherical particles with a specific density and diameter. However, these estimations do not account for the full MP continuum, which comprises different particle sizes, shapes, and densities. ${ }^{12,61}$ The single estimates used so far in simple risk assessment calculations ranged from 0.007 to $4 \mu \mathrm{g} /$ particle. ${ }^{6,20,37}$ These estimates are above the 85 th percentile of the mass distributions reported in the present study (Figures $\mathrm{S} 2 \mathrm{G}, \mathrm{H})$. Our estimates show that the mean values are $5.65 \times$ $10^{-6}$ and $3.97 \times 10^{-7} \mu \mathrm{g} /$ particle for food and air, respectively. This shows that previous studies have overestimated the MP exposure and potential risks.

Among the nine media, the highest median contribution of $\mathrm{MP}$ intake rate in terms of mass is from air, at $1.07 \times 10^{-7} \mathrm{mg} /$ capita/day. Despite the smaller size $(1-10 \mu \mathrm{m})$, the intake rates and MP abundance in air are much higher than other media (Figure 2C). At the 95th percentile, MP mass intake distribution from bottled water is the highest among all media, with intake rates of $1.96 \times 10^{-2} \mathrm{mg} /$ capita/day. Some countries are still very reliant on bottled water as their main source of drinking water since their piped water supplies may be contaminated and unsafe for consumption. Therefore, this source is an important route for MP exposure in these countries. The lowest median intake rate is from fish $(3.7 \times$ $10^{-10} \mathrm{mg} /$ capita/day). As mentioned earlier, this can be explained by the highest non-occurrence for fish and from the fact that the median number concentration of MP in fish muscle is only 0.18 particles/g BWW. This suggests that its relevance for MP intake is low relative to other known media.

The total daily median MP mass intakes from the nine media for children and adults are $1.84 \times 10^{-4}\left(1.28 \times 10^{-7}-\right.$ $7.5)$ and $5.83 \times 10^{-4}\left(3.28 \times 10^{-7}-17\right) \mathrm{mg} /$ capita/day, respectively. A recent report by the World Wildlife Fund (WWF) claimed that humans consume up to $5 \mathrm{~g}$ of plastic (one credit card) every week ( $\sim 700 \mathrm{mg} /$ capita/day) from a subset of our intake media (Figure 2C). ${ }^{101}$ Their estimation is above the 99th percentile of our distribution and hence, does not represent the intake of an average person. Other types of nano- and microparticles are also widely present in our diet, such as titanium dioxide and silicates. It is estimated that the dietary intake of these particles is about $40 \mathrm{mg} /$ capita/day in the U.K. ${ }^{102}$ Comparing our findings with the intake of other particles, MP mass intake rates are insignificant, as they make up for only $0.001 \%$ of these particles. However, this comparison does not imply that the toxicological profiles of these particles are similar.

Distribution of MP in Gut, Tissue, and Stool. MP accumulation in the gut, tissue, and stool was simulated over the average human lifetime ( 70 years) using the MP kinetic model under four scenarios (Figure 3). Previous studies have revealed that microsized particles between 1 and $20 \mu \mathrm{m}$ can be absorbed by the body through oral ingestion. $9,13,14,31-34,103$ Given this range of values, we assumed that MPs smaller than $10 \mu \mathrm{m}$ (i.e., midpoint of the range) are absorbed and distributed in the body then returned to the GI tract via biliary excretion, parameterized with a biliary excretion rate constant. Note that the cutoff at $10 \mu \mathrm{m}$ to some extent is arbitrary, as the model output obtained for a cutoff at $10 \mu \mathrm{m}$ can be easily converted to any other cutoff value using eq 4 . For the biliary excretion rate constant, four scenarios were simulated: no biliary excretion $\left(k_{\mathrm{tis}}=0 \mathrm{day}^{-1}\right)$, minimum $\left(k_{\mathrm{tis}}=\right.$ $\left.0.067 \mathrm{day}^{-1}\right)$, median $\left(k_{\mathrm{tis}}=0.61 \mathrm{~d}^{-1}\right)$, and maximum $\left(k_{\mathrm{tis}}=\right.$ $8.30 \mathrm{~d}^{-1}$ ) (Table S1). We observe that the MP steady-state abundance in the GI tract (i.e., at the end of the simulation for each age group) is not sensitive to this parameter $(p>0.05$; Kruskal-Wallis), whereas the accumulation of MP $(1-10 \mu \mathrm{m})$ in the tissue is significantly affected ( $p<0.05$; Kruskal-Wallis) (Figure 3A,B). This difference is due to the small contribution of accumulated particles in the tissues $\left(f_{\mathrm{abs}} \cdot f_{\mathrm{a}, n}\right.$ and $f_{\mathrm{abs}} \cdot f_{\mathrm{dep}} \approx$ $20 \%$ of total ingested MPs), which are excreted via the biliary 


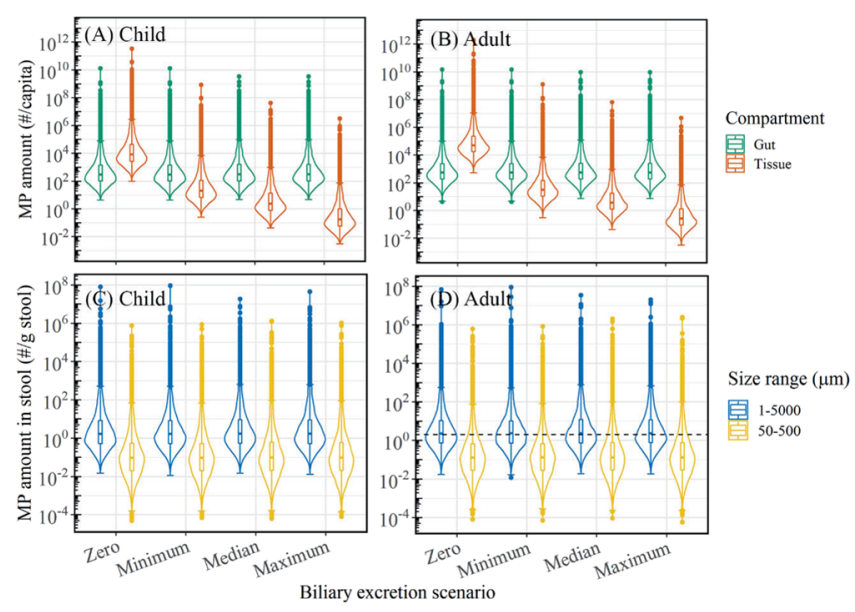

Figure 3. Distribution of MP amounts in the gut and tissue compartment at the end of the simulation for (A) a child (1-18 years) and (B) adult ( $1-70$ years). Scenarios: no biliary excretion $\left(k_{\text {tis }}\right.$ $\left.=0 \mathrm{~d}^{-1}\right)$, minimum $\left(k_{\mathrm{tis}}=0.067 \mathrm{~d}^{-1}\right)$, median $\left(k_{\mathrm{tis}}=0.61 \mathrm{~d}^{-1}\right)$, and maximum $\left(k_{\mathrm{tis}}=8.30 \mathrm{~d}^{-1}\right)$. Distribution of the amount egested in stools at the end of the simulation for (C) a child and (D) adult. Blue violin plots represent the full MP continuum, and yellow violin plots are scaled to the size range of 50-500 $\mu \mathrm{m}$ to compare with MP concentrations in stool from the study by Schwabl et al. ${ }^{8}$ (black dashed line). Note that data are only realistic within the $95 \%$ confidence interval (horizontal line on the whiskers of box plot).

pathway, to the number of particles already in the gut. In the worst case scenario where accumulated particles remain in the body throughout the lifetime (i.e., zero biliary excretion), the median concentration in the tissue is $5.01 \times 10^{4}\left(5.25 \times 10^{3}-\right.$ $\left.9.33 \times 10^{6}\right)$ particles/capita or $0.041\left(8.15 \times 10^{-4}-9.85\right) \mu \mathrm{g} /$ capita at the end of 70 years (Tables S9 and S10). The parameterization of this pathway is thus necessary to determine the extent of the MP exposure in the tissues and could be relevant for future effect studies. Note that biodistribution of the MPs among different organs of the body was not explicitly modeled, so this concentration relates to the whole body. In reality, the particles will accumulate in certain tissues and organs, potentially reaching much higher concentrations, locally. ${ }^{103-105}$

The MP abundances in the gut and tissue compartments were two to six times higher in adults than in children. Steadystate abundance was reached after $\sim 40$ days for each age group since the minimum biliary excretion rate (which is the ratelimiting process) is equivalent to a maximum half-life of 10 days. Therefore, even if a person lives beyond 70 years (i.e., past the model simulation time period), the abundance will not increase in both compartments, unless particles trapped in the body do not get eliminated as in the case for no biliary excretion. The median steady-state MP abundances in the gut are about 300 and 500 particles/capita for children and adults, respectively, which translate to mass abundances ranging from $7.98 \times 10^{-4}$ to $1.59 \times 10^{-3} \mu \mathrm{g} /$ capita (Tables S9 and S10). We then estimated the MP abundance in stool based on gut steady-state abundances (Figure 3C,D). This endpoint was chosen as it is comparable to the only MP occurrence study in humans to date. ${ }^{8}$ The median MP level $(50-500 \mu \mathrm{m})$ found in stools of adults aged between 33 and 65 years in the aforementioned study is 2 particles/g stool. ${ }^{8}$ This lies within the 80th percentile of our distribution for particles within the same size range. Comparing the median levels, our model estimates about $7 \%$ of the MP abundance found in the stool samples. This suggests that MP intake exposure may be higher than the intake amounts we estimate here based on known media. This is reasonable since the food types considered in the present study compose of $20 \%$ of the global average diet. $^{106}$

Weight of Evidence for the Role of MP as Chemical Vectors. The chemical contribution from MP to total

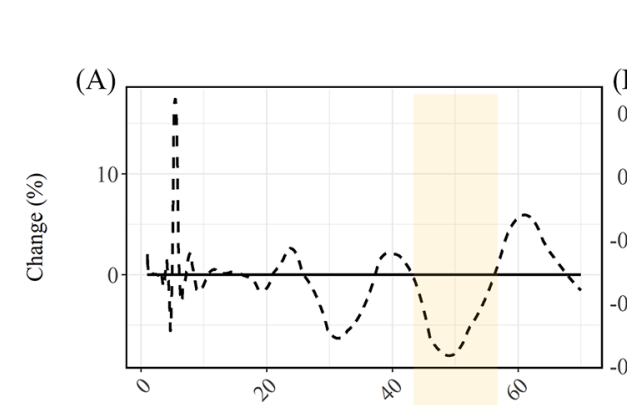

Percentile -50 th $--\cdot 97.5$ th
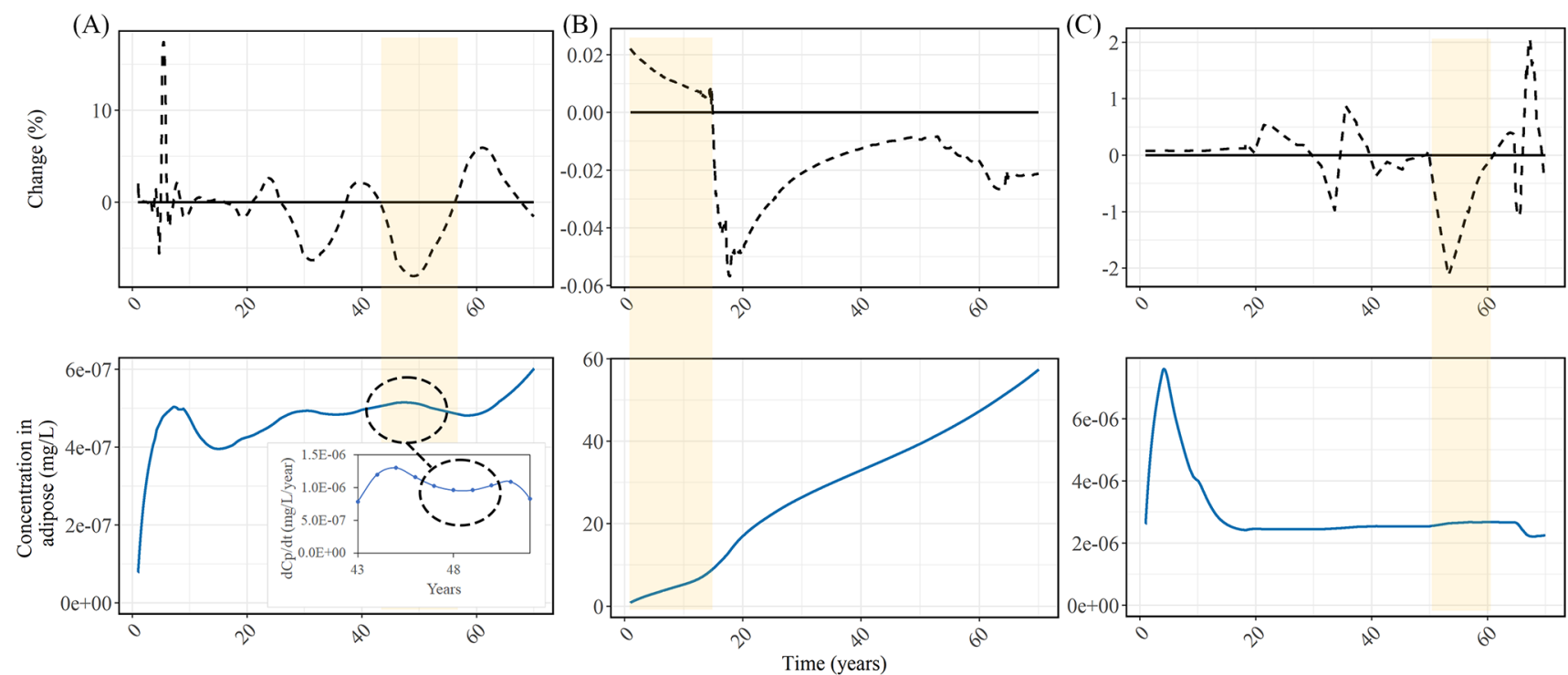

Figure 4. Percentage change of chemicals in adipose tissues as a result of additional chemical exposure via MPs (top panel) and the initial adipose tissue concentrations from dietary intake of compounds (bottom panel). (A) BaP; (B) DEHP; (C) PCB126. The yellow highlighted parts show how the percentage change varies depending on the change in adipose tissue concentrations. Inset in panel A shows the rate of change of chemical leaching from MPs for ages between 43 and 52 years to demonstrate that the maxima adipose tissue concentrations coincide with the minima of the leaching rate of chemicals from MPs. 
chemical intake was evaluated by probabilistically accounting for the full variability of ingested MP and chemical concentrations on the MP particles. Chemical leaching from MP was modeled assuming biphasic reversibility, where the direction of transfer is determined by the concentration gradients between MP and gut tissue, with kinetics determined by particle and chemical properties. In contrast, previous reports by the European Food Safety Authority (EFSA) ${ }^{37}$ and $\mathrm{WHO}^{6}$ were based on conservative calculations with highest chemical concentration detected in beached pellets and single MP intake measurements based on molluscs. ${ }^{107}$ The estimation was based on an average particle diameter and density and thus, not accounting for possibly slower kinetics from much larger particles.

With our integrated and more realistic chemical modeling approach, we demonstrate that at the 50th percentile of the chemical concentrations leached, the change in the tissue concentrations for the four chemicals is negligible (Figures 4 and S5). This also confirms our model assumption that chemical leaching from MP would not substantially affect the background chemical concentration in the gut originating from food. In the more extreme cases (i.e., at the 97.5th percentile of concentration leached from MPs), BaP showed the highest percentage change in the adipose tissue concentrations with a maximum of $17.4 \%$ increase (Figure 4A). PCB126 recorded the highest contribution from MP exposure to dietary intake $(\sim 0.12 \%$ at the 97.5 th percentile) among the analyzed chemicals (Data S6). However, it only resulted in a small change of $2 \%$ in the adipose tissues with additional exposure via MP. These results illustrate that the proportion of chemical exposure from MP intake to total dietary intake, which has usually been used to evaluate the role of the vector effect, ${ }^{6,20,37}$ is insufficient to inform us about the eventual chemical change in the body, due to the differences in biodistribution processes for different chemicals.

The percentage change of tissue concentrations appears to be erratic over the lifetime (Figure 4). Due to the processes simulated in the Man model, the chemicals in the body do not steadily increase over time (Figure 4 ). When there are higher concentrations in the adipose tissue, the gradient for transfer from the ingested MPs to the tissue is reduced and vice versa. Therefore, maxima in the adipose concentrations caused by dietary intake (lower panel A, yellow band), coincide with minima of the leaching rate of chemical from MPs (see the inset in Figure 4A). Interestingly, when the chemical leaching rate from MPs is at a minimum turning point, the additional chemical exposure via MPs results in a decrease in tissue concentrations (i.e., negative percentage change) compared to the zero plastic scenario (upper panel A, yellow band). Conversely, the additional chemical exposure from MPs results in an increase in tissue concentrations when the initial adipose concentrations are at a minimum (Figure 4B).

We simulated the percentage change of lead in blood assuming a constant percentage leaching from MPs over the lifetime, as the aforementioned biphasic kinetic model is not applicable for metals due to differences in chemical behaviour. ${ }^{77}$ In addition, unlike the other compounds, lead is usually measured in the blood for human exposure. The percentage contribution of lead from MP exposure to dietary intake is three to five orders of magnitude lower than the aforementioned organic compounds, at the 97.5th percentile. This resulted in a decreasing percentage change in the blood over time due to the increased proportion of the chemical body burden originating from dietary and inhalation intake (Figure S5). Before the age of 10 years, the percentage increase is greater than $5 \%$ and can reach up to almost $20 \%$. Lead is used widely in plastic as a stabilizer and also as a component of paint. $^{108}$ It has also been detected in plastic pellets and fragments in the marine environment. ${ }^{109-112}$ Because the contribution of MP in lead intake is not negligible, more studies are warranted to understand the transfer kinetics of lead in plastic under realistic gut conditions.

Outlook and General Implications. An MP human exposure assessment toolkit (HEASI) is presented, which applies innovative concepts and tools accounting for the uncertainty and variability of MPs. Previous human exposure assessments $^{1,2}$ have neglected the complexity of MP mixtures and did not take into account the discrepancies in the size ranges and methodologies of the studies used in the assessments. The HEASI toolkit also includes novel methods of translating MP number concentrations to mass concentrations using probabilistic calculations for the full MP continuum. We performed the assessment based on nine intake media that were available during the predefined period of our literature review. We found that the total MP intake rates from these nine media are negligible when compared to inorganic particles in terms of mass. Of the ingested MPs, the smaller-sized fraction $(1-10 \mu \mathrm{m})$ may be absorbed in the intestinal region and become trapped in the human body throughout the lifetime. In the case when there is limited biliary excretion, the trapped particles would reach higher mass concentrations in the whole body tissue than in the gut despite the small particle sizes. Our methodology also allows us to estimate the MP abundance in stools, an endpoint that can be used for future calibration of the model.

Previous risk assessments that evaluate the role of MPs as chemical vectors in humans have so far assumed worst case scenarios in their calculations, with $100 \%$ instantaneous leaching of chemicals. ${ }^{6,20,37}$ In the present study, we performed a probabilistic assessment to evaluate the actual chemical exposure via MPs in relation to dietary and inhalation intake of compounds using the simulated MP intake rates and also accounting for the full variability of the MP continuum. Our methodology also includes quantifying the actual percentage change in the body tissue concentrations with the added chemicals from MP intake. We conclude that the contribution of the MPs to chemical intake is small to negligible for the four representative chemicals investigated in this study and yet still not substantial for $\mathrm{BaP}(\sim 17 \%)$ and lead $(\sim 20 \%)$ at the 97.5 th percentile of the amount of chemicals leached.

As the biodistribution of MPs is still unknown to date, simulated concentrations of $1-10 \mu \mathrm{m} \mathrm{MP}$ in tissue relate to the whole body. However, if these MPs do get trapped, they may accumulate in specific tissues. In the research field of engineered nanoparticles, studies have identified the liver and spleen as main target organs for silver nanoparticles. ${ }^{113,114}$ Assuming that MPs behave similarly and accumulate mainly in the liver, we estimate that local concentration could reach up to $\sim 0.025 \mu \mathrm{g} / \mathrm{L}$ at the end of a human lifetime if there is no biliary excretion. Since there is no data on MP occurrence in human tissue specimens to date, our model can provide the best estimate of local tissue concentrations, which can be useful for future human effect studies.

At present, due to the paucity of data in other foods, our estimates of the MP intake rates account for approximately $20 \%$ by mass of the total food consumed daily on average (i.e., 
across different food cluster diets). ${ }^{106}$ As publications in the field of MPs increase exponentially, a few new studies reported MP occurrence in fruits and vegetables, ${ }^{115}$ and packaged meat $^{116}$ after our analysis date. However, these are only single datasets for each food category and thus do not fulfill our criteria for the present assessment. Between these food categories, the estimated daily intakes of particles from fruits and vegetables were higher, averaging at $1.50 \times 10^{7}$ particles/ capita/day (in adults with an average body weight of $70 \mathrm{~kg}$ ) with median sizes of about $2 \mu \mathrm{m} .{ }^{115}$ Based on our particle mass distribution in food, the mass of these small-sized particles would be less than $1 \times 10^{-7} \mu \mathrm{g} /$ particle. It is plausible that if these food categories are considered, our model would predict much higher MP mass concentrations accumulated in the body than our earlier predictions. However, even if this would increase up to seven orders of magnitude, this is still only $0.004 \%$ of the mass of inorganic particles ingested per day. ${ }^{102}$

\section{ASSOCIATED CONTENT}

\section{s) Supporting Information}

The Supporting Information is available free of charge at https://pubs.acs.org/doi/10.1021/acs.est.0c07384.

Additional information on materials and methods, supplementary text, Figures S1 to S5, Table S1 to 10; Data S1 to S6 can be found in the Github data depository: https://github.com/nhazimah/heasi; (Data S1) the database for MP abundance in nine intake media; (Data S2) the results of the goodness-of-fit tests; (Data S3) the database for MP shape fractions; (Data S4) the database for MP density; (Data S5) the database for chemical concentrations in environmental proxies; and (Data S6) the database for chemical intake data from food (PDF)

\section{AUTHOR INFORMATION}

\section{Corresponding Author}

Nur Hazimah Mohamed Nor - Aquatic Ecology and Water Quality Management Group, Department of Environmental Sciences, Wageningen University, 6700 AA Wageningen, The Netherlands; (1) orcid.org/0000-0002-8086-1833; Email: hazimah.mohamednor@wur.nl

\section{Authors}

Merel Kooi - Aquatic Ecology and Water Quality Management Group, Department of Environmental Sciences, Wageningen University, 6700 AA Wageningen, The Netherlands; orcid.org/0000-0003-0092-5209

Noël J. Diepens - Aquatic Ecology and Water Quality Management Group, Department of Environmental Sciences, Wageningen University, 6700 AA Wageningen, The Netherlands; 1 orcid.org/0000-0001-9159-7276

Albert A. Koelmans - Aquatic Ecology and Water Quality Management Group, Department of Environmental Sciences, Wageningen University, 6700 AA Wageningen, The Netherlands; (1) orcid.org/0000-0001-7176-4356

Complete contact information is available at: https://pubs.acs.org/10.1021/acs.est.0c07384

\section{Notes}

The authors declare no competing financial interest.

\section{ACKNOWLEDGMENTS}

We would like to thank Yayasan Mendaki (Singapore) for the Ridzwan Dzafir Distinction Award, the PMBM Scholarship Fund Board (Singapore), and the Aquatic Ecology and Water Quality group of Wageningen University and Research for cofunding this project.

\section{REFERENCES}

(1) Zhang, Q.; Xu, E. G.; Li, J.; Chen, Q.; Ma, L.; Zeng, E. Y.; Shi, H. A Review of Microplastics in Table Salt, Drinking Water, and Air: Direct Human Exposure. Environ. Sci. Technol. 2020, 3740.

(2) Cox, K. D.; Covernton, G. A.; Davies, H. L.; Dower, J. F.; Juanes, F.; Dudas, S. E. Human Consumption of Microplastics. Environ. Sci. Technol. 2019, 53, 7068-7074.

(3) EFSA. Presence of Microplastics and Nanoplastics in Food, with Particular Focus on Seafood EFSA Panel on Contaminants in the Food Chain ( CONTAM ). EFSA J. 2016, 14, e04501.

(4) Barboza, L. G. A.; Vethaak, A. D.; Lavorante, B. R. B. O.; Lundebye, A.-K.; Guilhermino, L. Marine Microplastic Debris : An Emerging Issue for Food Security, Food Safety and Human Health. Mar. Pollut. Bull. 2018, 133, 336-348.

(5) Peixoto, D.; Pinheiro, C.; Amorim, J.; Oliva-Teles, L.; Guilhermino, L.; Vieira, M. N. Microplastic Pollution in Commercial Salt for Human Consumption : A Review. Estuar. Coast. Shelf Sci. January 2018, 219, 161-168.

(6) World Health Organization Microplastics in Drinking-Water; 2019. ISBN: 978-92-4-151619-8

(7) Enyoh, C. E.; Verla, A. W.; Verla, E. N.; Ibe, F. C.; Amaobi, C. E. Airborne Microplastics: A Review Study on Method for Analysis, Occurrence, Movement and Risks. Environ. Monit. Assess. 2019, 668.

(8) Schwabl, P.; Köppel, S.; Königshofer, P.; Bucsics, T.; Trauner, M.; Reiberger, T.; Liebmann, B. Detection of Various Microplastics in Human Stool: A Prospective Case Series. Ann. Intern. Med. 2019, 453.

(9) Wright, S. L.; Kelly, F. J. Plastic and Human Health: A Micro Issue? Environ. Sci. Technol. 2017, 51, 6634-6647.

(10) Rodrigues, M. O.; Abrantes, N.; Gonçalves, F. J. M.; Nogueira, H.; Marques, J. C.; Gonçalves, A. M. M. Impacts of Plastic Products Used in Daily Life on the Environment and Human Health: What Is Known? Environ. Toxicol. Pharmacol. 2019, 103239.

(11) Hartmann, N. B.; Hüffer, T.; Thompson, R. C.; Hassellöv, M.; Verschoor, A.; Daugaard, A. E.; Rist, S.; Karlsson, T.; Brennholt, N.; Cole, M.; Herrling, M. P.; Hess, M. C.; Ivleva, N. P.; Lusher, A. L.; Wagner, M. Are We Speaking the Same Language? Recommendations for a Definition and Categorization Framework for Plastic Debris. Environ. Sci. Technol. 2019, 1039.

(12) Koelmans, A. A.; Redondo-Hasselerharm, P. E.; Mohamed Nor, N. H.; Kooi, M. Solving the Non-Alignment of Methods and Approaches Used in Microplastic Research in Order to Consistently Characterize Risk. Environ. Sci. Technol. 2020, 54, 12307-12315.

(13) van Raamsdonk, L. W. D.; van der Zande, M.; Koelmans, A. A.; Hoogenboom, R. P. L. A.; Peters, R. J. B.; Groot, M. J.; Peijnenburg, A. A. C. M.; Weesepoel, Y. J. A. Current Insights into Monitoring, Bioaccumulation, and Potential Health Effects of Microplastics Present in the Food Chain. Foods. 2020, 72.

(14) Stock, V.; Böhmert, L.; Lisicki, E.; Block, R.; Cara-Carmona, J.; Pack, L. K.; Selb, R.; Lichtenstein, D.; Voss, L.; Henderson, C. J.; Zabinsky, E.; Sieg, H.; Braeuning, A.; Lampen, A. Uptake and Effects of Orally Ingested Polystyrene Microplastic Particles in Vitro and in Vivo. Arch. Toxicol. 2019, 1817.

(15) Hesler, M.; Aengenheister, L.; Ellinger, B.; Drexel, R.; Straskraba, S.; Jost, C.; Wagner, S.; Meier, F.; von Briesen, H.; Büchel, C.; Wick, P.; Buerki-Thurnherr, T.; Kohl, Y. Multi-Endpoint Toxicological Assessment of Polystyrene Nano- and Microparticles in Different Biological Models in Vitro. Toxicol. Vitr. 2019, 104610.

(16) Hwang, J.; Choi, D.; Han, S.; Choi, J.; Hong, J. An Assessment of the Toxicity of Polypropylene Microplastics in Human Derived Cells. Sci. Total Environ. 2019, 657. 
(17) Schirinzi, G. F.; Pérez-Pomeda, I.; Sanchís, J.; Rossini, C.; Farré, M.; Barceló, D. Cytotoxic Effects of Commonly Used Nanomaterials and Microplastics on Cerebral and Epithelial Human Cells. Environ. Res. 2017, 579.

(18) Groh, K. J.; Backhaus, T.; Carney-Almroth, B.; Geueke, B.; Inostroza, P. A.; Lennquist, A.; Leslie, H. A.; Maffini, M.; Slunge, D.; Trasande, L.; Warhurst, A. M.; Muncke, J. Overview of Known Plastic Packaging-Associated Chemicals and Their Hazards. Sci. Total Environ. 2019, 3253.

(19) Koelmans, A. A.; Bakir, A.; Burton, G. A.; Janssen, C. R. Microplastic as a Vector for Chemicals in the Aquatic Environment: Critical Review and Model-Supported Reinterpretation of Empirical Studies. Environ. Sci. Technol. 2016, 50, 3315-3326.

(20) Food and Agriculture Organization of the United Nations. Microplastics in Fisheries and Aquaculture Status of Knowledge on Their Occurrence and Implications for Aquatic Organisms and Food Safety; 2017.

(21) Koch, H. M.; Calafat, A. M. Human Body Burdens of Chemicals Used in Plastic Manufacture. Philos. Trans. R. Soc., B 2009, 2063.

(22) Koelmans, A. A.; Besseling, E.; Foekema, E.; Kooi, M.; Mintenig, S.; Ossendorp, B. C.; Redondo-Hasselerharm, P. E.; Verschoor, A.; Van Wezel, A. P.; Scheffer, M. Risks of Plastic Debris: Unravelling Fact, Opinion, Perception, and Belief. Environ. Sci. Technol. 2017, 11513.

(23) Erythropel, H. C.; Maric, M.; Nicell, J. A.; Leask, R. L.; Yargeau, V. Leaching of the Plasticizer Di(2-Ethylhexyl)Phthalate (DEHP) from Plastic Containers and the Question of Human Exposure. Appl. Microbiol. Biotechnol. 2014, 9967.

(24) Kim, K. C.; Park, Y. B.; Lee, M. J.; Kim, J. B.; Huh, J. W.; Kim, D. H.; Lee, J. B.; Kim, J. C. Levels of Heavy Metals in Candy Packages and Candies Likely to Be Consumed by Small Children. Food Res. Int. 2008, 411.

(25) Hussain, K.; Hoque, R. R.; Balachandran, S.; Medhi, S.; Idris, M. G.; Rahman, M.; Hussain, F. L. Monitoring and Risk Analysis of PAHs in the Environment. In Handbook of Environmental Materials Management; 2019, DOI: 10.1007/978-3-319-73645-7 29.

(26) Eriksson, E.; Baun, A.; Scholes, L.; Ledin, A.; Ahlman, S.; Revitt, M.; Noutsopoulos, C.; Mikkelsen, P. S. Selected Stormwater Priority Pollutants - a European Perspective. Sci. Total Environ. 2007, 41.

(27) Eljarrat, E.; Barceló, D. Priority Lists for Persistent Organic Pollutants and Emerging Contaminants Based on Their Relative Toxic Potency in Environmental Samples. TrAC - Trends Anal. Chem. 2003, 655 .

(28) Wani, A. L.; Ara, A.; Usmani, J. A. Lead Toxicity: A Review. Interdisciplinary Toxicology. 2015, 55.

(29) Herzke, D.; Anker-Nilssen, T.; Nøst, T. H.; Götsch, A.; Christensen-Dalsgaard, S.; Langset, M.; Fangel, K.; Koelmans, A. A. Negligible Impact of Ingested Microplastics on Tissue Concentrations of Persistent Organic Pollutants in Northern Fulmars off Coastal Norway. Environ. Sci. Technol. 2016, 50, 1924-1933.

(30) Diepens, N. J.; Koelmans, A. A. Accumulation of Plastic Debris and Associated Contaminants in Aquatic Food Webs. Environ. Sci. Technol. 2018, 52, 8510-8520.

(31) Rieux, A. D.; Ragnarsson, E. G. E.; Gullberg, E.; Préat, V.; Schneider, Y. J.; Artursson, P. Transport of Nanoparticles across an in Vitro Model of the Human Intestinal Follicle Associated Epithelium. Eur. J. Pharm. Sci. 2005, 25, 455-465.

(32) Mowat, A. M. I. Anatomical Basis of Tolerance and Immunity to Intestinal Antigens. Nat. Rev. Immunol. 2003, 3, 331-341.

(33) Hodges, G. M.; Carr, E. A.; Hazzard, R. A.; Carr, K. E. Uptake and Translocation of Microparticles in Small Intestine - Morphology and Quantification of Particle Distribution. Dig. Dis. Sci. 1995, 40, 967-975.

(34) Jani, P. U.; McCarthy, D. E.; Florence, A. T. Nanosphere and Microsphere Uptake via Peyer's Patches: Observation of the Rate of Uptake in the Rat after a Single Oral Dose. Int. J. Pharm. 1992, 239.
(35) Carr, K. E.; Smyth, S. H.; McCullough, M. T.; Morris, J. F.; Moyes, S. M. Morphological Aspects of Interactions between Microparticles and Mammalian Cells: Intestinal Uptake and Onward Movement. Prog. Histochem. Cytochem. 2012, 185.

(36) Doyle-McCullough, M.; Smyth, S. H.; Moyes, S. M.; Carr, K. E. Factors Influencing Intestinal Microparticle Uptake in Vivo. Int. J. Pharm. 2007, 79.

(37) EFSA. Presence of Microplastics and Nanoplastics in Food, with Particular Focus on Seafood. EFSA J. 2016, 14, e04501.

(38) Schmidt, C.; Lautenschlaeger, C.; Collnot, E. M.; Schumann, M.; Bojarski, C.; Schulzke, J. D.; Lehr, C. M.; Stallmach, A. Nano- and Microscaled Particles for Drug Targeting to Inflamed Intestinal Mucosa - A First in Vivo Study in Human Patients. J. Controlled Release 2013, 139.

(39) Fry, F. A.; Black, A. Regional Deposition and Clearance of Particles in the Human Nose. J. Aerosol Sci. 1973, 113.

(40) Gigault, J.; ter Halle, A.; Baudrimont, M.; Pascal, P.-Y.; Gauffre, F.; Phi, T.-L.; el Hadri, H.; Grassl, B.; Reynaud, S. Current Opinion: What Is a Nanoplastic? Environ. Pollut. 2018, 1030.

(41) Ogawara, K. I.; Yoshida, M.; Kubo, J. I.; Nishikawa, M.; Takakura, Y.; Hashida, M.; Higaki, K.; Kimura, T. Mechanisms of Hepatic Disposition of Polystyrene Microspheres in Rats: Effects of Serum Depend on the Sizes of Microspheres. J. Controlled Release 1999, 61, 241-250.

(42) von Goetz, N.; Bachler, G.; Hungerbühler, K. A Physiologically Based Pharmacokinetic Model for Ionic Silver and Silver Nanoparticles. Int. J. Nanomed. 2013, 8, 3365-3382.

(43) Reineke, J.; Li, M.; Avgoustakis, K. Physiologically Based Pharmacokinetic Modeling of PLGA Nanoparticles with Varied MPEG Content. Int. J. Nanomed. 2012, 7, 1345-1356.

(44) Martelli, H.; Devroede, G.; Arhan, P.; Duguay, C.; Dornic, C.; Faverdin, C. Some Parameters of Large Bowel Motility in Normal Man. Gastroenterology 1978, 75, 612-618.

(45) Walter, S. A.; Kjellström, L.; Nyhlin, H.; Talley, N. J.; Agréus, L. Assessment of Normal Bowel Habits in the General Adult Population: The Popcol Study. Scand. J. Gastroenterol. 2010, 556.

(46) Sujatha, B.; Velayutham, D. R.; Deivamani, N.; Bavanandam, S. Normal Bowel Pattern in Children And Dietary and Other Precipitating Factors in Functional Constipation. J. Clin. Diagn. Res. 2015, DOI: $10.7860 / J C D R / 2015 / 13290.6025$.

(47) Weaver, L. T.; Steiner, H. The Bowel Habit of Young Children. Arch. Dis. Child. 1984, 649.

(48) Corazziari, E.; Staiano, A.; Miele, E.; Greco, L. Bowel Frequency and Defecatory Patterns in Children: A Prospective Nationwide Survey. Clin. Gastroenterol. Hepatol. 2005, 1101.

(49) Kyaw-Hla, S.; Bolin, T. D. A Prospective Study on Defecation Frequency, Stool Weight, and Consistency. Arch. Dis. Child. 1994, 311.

(50) Williams, C. L.; Bollella, M. C.; Strobino, B. A.; Boccia, L.; Campanaro, L. Plant Stanol Ester and Bran Fiber in Childhood: Effects on Lipids, Stool Weight and Stool Frequency in Preschool Children. J. Am. Coll. Nutr. 1999, 18, 572-581.

(51) Asl, S.; Hosseini, S. Determination of the Mean Daily Stool Weight, Frequency of Defecation and Bowel Transit Time: Assessment of 1000 Healthy Subjects. Arch Iran. Med. www. ams. ac. ir/AIM/ ... 2000 .

(52) Rose, C.; Parker, A.; Jefferson, B.; Cartmell, E. The Characterization of Feces and Urine: A Review of the Literature to Inform Advanced Treatment Technology. Crit. Rev. Environ. Sci. Technol. 2015, 45, 1827-1879.

(53) MacLennan, R.; Jensen, O. M.; Mosbech, J.; Vuori, H. Diet, Transit Time, Stool Weight, and Colon Cancer in Two Scandinavian Populations. Am. J. Clin. Nutr. 1978, 31, 3-S242.

(54) WHO FOSCOLLAB: Global platform for food safety data and information http://www.who.int/foodsafety/foscollab_dashboards/ en/.

(55) Stifelman, M. Using Doubly-Labeled Water Measurements of Human Energy Expenditure to Estimate Inhalation Rates. Sci. Total Environ. 2007, 373, 585-590. 
(56) Allan, M.; Richardson, G. M. Human and Ecological Risk Assessment : An International Probability Density Functions Describing 24-Hour Inhalation Rates For Use in Human Health Risk Assessments Probability Density Functions Describing 24-Hour Inhalation Rates For Use in Human Health Ri. 2010, 7039, DOI: 10.1080/ 10807039891284389.

(57) Koelmans, A. A.; Mohamed Nor, N. H.; Hermsen, E.; Kooi, M.; Mintenig, S. M.; De France, J. Microplastics in Freshwaters and Drinking Water: Critical Review and Assessment of Data Quality. Water Res. 2019, 410.

(58) Hermsen, E.; Mintenig, S. M.; Besseling, E.; Koelmans, A. A. Quality Criteria for the Analysis of Microplastic in Biota Samples: A Critical Review. Environ. Sci. Technol. 2018, 10230.

(59) Lenz, R.; Enders, K.; Stedmon, C. A.; MacKenzie, D. M. A.; Nielsen, T. G. A Critical Assessment of Visual Identification of Marine Microplastic Using Raman Spectroscopy for Analysis Improvement. Mar. Pollut. Bull. 2015, 82.

(60) Cózar, A.; Echevarría, F.; González-Gordillo, J. I.; Irigoien, X.; Úbeda, B.; Hernández-León, S.; Palma, A. T.; Navarro, S.; García-deLomas, J.; Ruiz, A.; Fernández-de-Puelles, M. L.; Duarte, C. M. Plastic Debris in the Open Ocean. Proc. Natl. Acad. Sci. U. S. A. 2014, 10239.

(61) Kooi, M.; Koelmans, A. A. Simplifying Microplastic via Continuous Probability Distributions for Size, Shape,and Density. Environ. Sci. Technol. Lett. 2019, 551.

(62) R Core Team R: A Language and Environment for Statistical Computing. $R$ Foundation for Statistical Computing. Vienna, Austria 2019.

(63) Abbasi, S.; Soltani, N.; Keshavarzi, B.; Moore, F.; Turner, A.; Hassanaghaei, M. Microplastics in Different Tissues of Fish and Prawn from the Musa Estuary, Persian Gulf. Chemosphere 2018, 205, 80-87.

(64) Barboza, L. G. A.; Lopes, C.; Oliveira, P.; Bessa, F.; Otero, V.; Henriques, B.; Raimundo, J.; Caetano, M.; Vale, C.; Guilhermino, L. Microplastics in Wild Fish from North East Atlantic Ocean and Its Potential for Causing Neurotoxic Effects, Lipid Oxidative Damage, and Human Health Risks Associated with Ingestion Exposure. Sci. Total Environ. 2020, 717, 134625 .

(65) Delignette-Muller, M. L.; Dutang, C. Fitdistrplus: An R Package for Fitting Distributions. J. Stat. Softw. 2015, 64, 1-34.

(66) Azzalini, A. The R Package "Sn": The Skew-Normal and Related Distributions Such as the Skew-t (Version 1.6-2). 2020.

(67) Dutang, C.; Goulet, V.; Pigeon, M. Actuar: An R Package for Actuarial Science. J. Stat. Softw. 2008, 25, 1-37.

(68) Benaglia, T.; Chauveau, D.; Hunter, D. R.; Young, D. Mixtools: An R Package for Analyzing Finite Mixture Models. J. Stat. Softw. 2009, 32, 1-29.

(69) Soetaert, K.; Petzoldt, T.; Setzer, R. W. Solving Differential Equations in R : Package DeSolve. J. Stat. Softw. 2010, 33, 1, DOI: $10.18637 /$ jss.v033.i09.

(70) Brochot, C.; Quindroit, P. Modelling the Fate of Chemicals in Humans Using a Lifetime Physiologically Based Pharmacokinetic (PBPK) Model in MERLIN-Expo. In Handbook of Environmental Chemistry; 2018, DOI: 10.1007/978-3-319-59502-3 10.

(71) Mohamed Nor, N. H.; Koelmans, A. A. Transfer of PCBs from Microplastics under Simulated Gut Fluid Conditions Is Biphasic and Reversible. Environ. Sci. Technol. 2019, 53, 1874-1883.

(72) Marques, M. R. C.; Loebenberg, R.; Almukainzi, M. Simulated Biological Fluids with Possible Application in Dissolution Testing. Dissolution Technol 2011, 18, 15-28.

(73) Saunders, D. R.; Ways, P. O.; Parmentier, C. M.; Rubin, C. E. Studies on the Lipid Composition of Human Small Bowel Mucosa. J. Clin. Invest. 1966, 1516.

(74) Hawker, D. W.; Connell, D. W. Octanol-Water Partition Coefficients of Polychlorinated Biphenyl Congeners. Environ. Sci. Technol. 1988, 22, 382-387.

(75) De Maagd, P. G. J.; Ten Hulscher, D. T. E. M.; Van Den Heuvel, H.; Opperhuizen, A.; Sijm, D. T. H. M. Physicochemical Properties of Polycyclic Aromatic Hydrocarbons: Aqueous Solubilities, n-Octanol/Water Partition Coefficients, and Henry's Law
Constants. In Environmental Toxicology and Chemistry; 1998, DOI: 10.1897/1551-5028(1998)017<0251:PPOPAH>2.3.CO;2.

(76) De Bruijn, J.; Busser, F.; Seinen, W.; Hermens, J. Determination of Octanol/Water Partition Coefficients for Hydrophobic Organic Chemicals with the "Slow-stirring" Method. Environ. Toxicol. Chem. 1989, 499.

(77) Godoy, V.; Martínez-Férez, A.; Martín-Lara, M. Á.; VellidoPérez, J. A.; Calero, M.; Blázquez, G. Microplastics as Vectors of Chromium and Lead during Dynamic Simulation of the Human Gastrointestinal Tract. Sustain. 2020, 4792.

(78) Lee, B. M.; Shim, G. A. Dietary Exposure Estimation of Benzo[a]Pyrene and Cancer Risk Assessment. J. Toxicol. Environ. Heal. - Part A Curr. Issues 2007, 70, 1391-1394.

(79) Hong, W. J.; Jia, H.; Ma, W. L.; Sinha, R. K.; Moon, H. B.; Nakata, H.; Minh, N. H.; Chi, K. H.; Li, W. L.; Kannan, K.; Sverko, E.; Li, Y. F. Distribution, Fate, Inhalation Exposure and Lung Cancer Risk of Atmospheric Polycyclic Aromatic Hydrocarbons in Some Asian Countries. Environ. Sci. Technol. 2016, 7163.

(80) Heinemeyer, G.; Sommerfeld, C.; Springer, A.; Heiland, A.; Lindtner, O.; Greiner, M.; Heuer, T.; Krems, C.; Conrad, A. Estimation of Dietary Intake of Bis(2-Ethylhexyl)Phthalate (DEHP) by Consumption of Food in the German Population. Int. J. Hyg. Environ. Health 2013, 472.

(81) Fromme, H.; Lahrz, T.; Piloty, M.; Gebhart, H.; Oddoy, A.; Rüden, H. Occurrence of Phthalates and Musk Fragrances in Indoor Air and Dust from Apartments and Kindergartens in Berlin (Germany). Indoor Air 2004, 188.

(82) Xie, Z.; Selzer, J.; Ebinghaus, R.; Caba, A.; Ruck, W. Development and Validation of a Method for the Determination of Trace Alkylphenols and Phthalates in the Atmosphere. Anal. Chim. Acta 2006, 198.

(83) Llobet, J. M.; Bocio, A.; Domingo, J. L.; Teixidó, A.; Casas, C.; Müller, L. Levels of Polychlorinated Biphenyls in Foods from Catalonia, Spain: Estimated Dietary Intake. J. Food Prot. 2003, 479.

(84) Malavolti, M.; Fairweather-Tait, S. J.; Malagoli, C.; Vescovi, L.; Vinceti, M.; Filippini, T. Lead Exposure in an Italian Population: Food Content, Dietary Intake and Risk Assessment. Food Res. Int. 2020, 137, 109370.

(85) Komarnicki, G. J. K. Lead and Cadmium in Indoor Air and the Urban Environment. Environ. Pollut. 2005, 47.

(86) Xu, Q.; Zhu, X.; Henkelmann, B.; Schramm, K. W.; Chen, J.; Ni, Y.; Wang, W.; Pfister, G.; Mu, J.; Qin, S.; Li, Y. Simultaneous Monitoring of PCB Profiles in the Urban Air of Dalian, China with Active and Passive Samplings. J. Environ. Sci. (China) 2013, 133.

(87) Minekus, M.; Alminger, M.; Alvito, P.; Ballance, S.; Bohn, T.; Bourlieu, C.; Carriére, F.; Boutrou, R.; Corredig, M.; Dupont, D.; Dufour, C.; Egger, L.; Golding, M.; Karakaya, S.; Kirkhus, B.; Le Feunteun, S.; Lesmes, U.; MacIerzanka, A.; MacKie, A.; Marze, S.; McClements, D. J.; Ménard, O.; Recio, I.; Santos, C. N.; Singh, R. P.; Vegarud, G. E.; Wickham, M. S. J.; Weitschies, W.; Brodkorb, A. A Standardised Static in Vitro Digestion Method Suitable for Food-an International Consensus. Food Funct. 2014, 1113.

(88) Gouin, T.; Roche, N.; Lohmann, R.; Hodges, G. A Thermodynamic Approach for Assessing the Environmental Exposure of Chemicals Absorbed to Microplastic. Environ. Sci. Technol. 2011, $45,1466-1472$.

(89) Koelmans, A. A.; Besseling, E.; Wegner, A.; Foekema, E. M. Plastic as a Carrier of POPs to Aquatic Organisms: A Model Analysis. Environ. Sci. Technol. 2013, 47, 7812-7820.

(90) Li, Y.; Shao, L.; Wang, W.; Zhang, M.; Feng, X.; Li, W.; Zhang, D. Airborne Fiber Particles: Types, Size and Concentration Observed in Beijing. Sci. Total Environ. 2020, 705, 135967.

(91) Vianello, A.; Jensen, R. L.; Liu, L.; Vollertsen, J. Simulating Human Exposure to Indoor Airborne Microplastics Using a Breathing Thermal Manikin. Sci. Rep. 2019, 9, 1.

(92) Timár, G.; Blömer, J.; Kun, F.; Herrmann, H. J. New Universality Class for the Fragmentation of Plastic Materials. Phys. Rev. Lett. 2010, 104, No. 095502. 
(93) Setälä, O.; Norkko, J.; Lehtiniemi, M. Feeding Type Affects Microplastic Ingestion in a Coastal Invertebrate Community. Mar. Pollut. Bull. 2016, 95.

(94) Wang, J.; Wang, M.; Ru, S.; Liu, X. High Levels of Microplastic Pollution in the Sediments and Benthic Organisms of the South Yellow Sea, China. Sci. Total Environ. 2019, 651, 1661-1669.

(95) Welle, F.; Franz, R. Microplastic in Bottled Natural Mineral Water-Literature Review and Considerations on Exposure and Risk Assessment. Food Addit. Contam. - Part A Chem. Anal. Control. Expo. Risk Assess. 2018, 2482.

(96) Liebezeit, G.; Liebezeit, E. Synthetic Particles as Contaminants in German Beers. Food Addit. Contam. - Part A Chem. Anal. Control. Expo. Risk Assess. 2014, 31, 1574-1578.

(97) Kosuth, M.; Mason, S. A.; Wattenberg, E. V. Anthropogenic Contamination of Tap Water, Beer, and Sea Salt. PLoS One 2018, 13, e0194970.

(98) Kutralam-Muniasamy, G.; Pérez-Guevara, F.; Elizalde-Martínez, I.; Shruti, V. C. Branded Milks - Are They Immune from Microplastics Contamination? Sci. Total Environ. 2020, 714, 136823.

(99) World Health Organization. Air Quality Guidelines Global Update 2005; 2006, DOI: 10.1007/BF02986808.

(100) World Health Organisation WHO Global Ambient Air Quality Database (Update 2018); 2018.

(101) Senathirajah, K.; Attwood, S.; Bhagwat, G.; Carbery, M.; Wilson, S.; Palanisami, T. Estimation of the Mass of Microplastics Ingested - A Pivotal First Step towards Human Health Risk Assessment. J. Hazard. Mater. 2020, 124004.

(102) Powell, J. J.; Faria, N.; Thomas-McKay, E.; Pele, L. C. Origin and Fate of Dietary Nanoparticles and Microparticles in the Gastrointestinal Tract. J. Autoimmun. 2010, J226.

(103) Deng, Y.; Zhang, Y.; Lemos, B.; Ren, H. Tissue Accumulation of Microplastics in Mice and Biomarker Responses Suggest Widespread Health Risks of Exposure. Sci. Rep. 2017, DOI: 10.1038/ srep46687.

(104) Deng, Y.; Zhang, Y.; Qiao, R.; Bonilla, M. M.; Yang, X.; Ren, H.; Lemos, B. Evidence That Microplastics Aggravate the Toxicity of Organophosphorus Flame Retardants in Mice (Mus Musculus). J. Hazard. Mater. 2018, 348.

(105) Yang, Y. F.; Chen, C. Y.; Lu, T. H.; Liao, C. M. Toxicity-Based Toxicokinetic/Toxicodynamic Assessment for Bioaccumulation of Polystyrene Microplastics in Mice. J. Hazard. Mater. 2019, 703.

(106) Héraud, F.; Barraj, L. M.; Moy, G. G. GEMS/Food Consumption Cluster Diets. Total Diet Stud. 2013, 427-434.

(107) Li, J.; Qu, X.; Su, L.; Zhang, W.; Yang, D.; Kolandhasamy, P.; Li, D.; Shi, H. Microplastics in Mussels along the Coastal Waters of China. Environ. Pollut. 2016, 214, 177-184.

(108) Coyle, P.; Kosnett, M. J.; Hipkins, K. Severe Lead Poisoning in the Plastics Industry: A Report of Three Cases. Am. J. Ind. Med. 2005, 172.

(109) Ashton, K.; Holmes, L.; Turner, A. Association of Metals with Plastic Production Pellets in the Marine Environment. Mar. Pollut. Bull. 2010, 2050.

(110) Holmes, L. A.; Turner, A.; Thompson, R. C. Adsorption of Trace Metals to Plastic Resin Pellets in the Marine Environment. Environ. Pollut. 2012, 160, 42-48.

(111) Massos, A.; Turner, A. Cadmium, Lead and Bromine in Beached Microplastics. Environ. Pollut. 2017, 227, 139-145.

(112) Carbery, M.; MacFarlane, G. R.; O’Connor, W.; Afrose, S.; Taylor, H.; Palanisami, T. Baseline Analysis of Metal(Loid)s on Microplastics Collected from the Australian Shoreline Using Citizen Science. Mar. Pollut. Bull. 2020, 110914.

(113) Gaillet, S.; Rouanet, J. M. Silver Nanoparticles: Their Potential Toxic Effects after Oral Exposure and Underlying Mechanisms - A Review. Food Chem. Toxicol. 2015, 58.

(114) Jani, P.; Halbert, G. W.; Langridge, J.; Florence, A. T. Nanoparticle Uptake by the Rat Gastrointestinal Mucosa: Quantitation and Particle Size Dependency. J. Pharm. Pharmacol. 1990, 821.

(115) Oliveri Conti, G.; Ferrante, M.; Banni, M.; Favara, C.; Nicolosi, I.; Cristaldi, A.; Fiore, M.; Zuccarello, P. Micro- and Nano-
Plastics in Edible Fruit and Vegetables. The First Diet Risks Assessment for the General Population. Environ. Res. 2020, 109677.

(116) Kedzierski, M.; Lechat, B.; Sire, O.; Le Maguer, G.; Le Tilly, V.; Bruzaud, S. Microplastic Contamination of Packaged Meat: Occurrence and Associated Risks. Food Packag. Shelf Life 2020, 100489. 